\title{
An Electrical Energy Audit of Water Pumping Machines
}

\author{
Bashir Garba. I. ${ }^{1, *}$, Yus uf Jibril ${ }^{2}$, Laminu S. $\mathbf{K}^{3}$ \\ ${ }^{1}$ Department of Maintenance and Services, Ahmadu Bello University, Zaria, 234, Nigeria \\ ${ }^{2}$ Dep artment Electrical En gin eering, Ahmadu Bello University, Zaria, 234, Nigeria \\ ${ }^{3}$ Department Mechanical En gin eering, Ahmadu Bello University, Zaria, 234, Nigeria
}

\begin{abstract}
The study involves an energy audit of Pumps used to pump fluid from lower level to higher level by using electrical energy. A case study was conducted on centrifugal pumps at Ahmadu Bello University Water treatment plant, series of energy audit was conducted to record various parameters viz., discharge, pressure, voltage, current, power, power factor and efficiencies to calculate the total electrical energy consumption per day and total actual energy use per day, maximum (VA )demand, maximum (KW )demand, consumption figures of the whole pump in the plant, energy cost figures of the plant in $(\mathrm{KWh})$, where we discovered very high energy wastage during operation .Therefore ways to reduce energy consumption by the replacement of the present pumps with inverter compatible energy efficient pu mps and various conservation methods are recommended for optimum utilization, this study will help other pump ing stations.
\end{abstract}

Keywords Pumps Operation, Energy Consumption, Audit, Energy Conservation Methods

\section{Introduction}

An energy audit is the study of a plant or facility to determine how and where energy is used and identify methods for energy savings. There is now a universal recognition of the fact that new technologies and much greater use of some that already existed provide the most hopeful prospect for the future opportunities lie in the use of existing renewable energy technology, greater efforts at energy efficiency and the dissemination of these technologies and options. This energy audit of the water works at Ahmadu Bello University samaru main campus with emphases to electrical energy consumption in the pump stations is a step towards our destination of achieving energy efficiency and would like to emphasize that an energy audit is a continuous process, in th is regard the research list possible actions to conserve and efficiently utilize our scares resources and identify various savings potentials .Over the years ,there has been significant progress at the university in all academic and research activities, and parallel improvement in facilities and infrastructure, without any improvement in the water treatment section and the present capacity cannot sustain the university couple with high electricity problems of low voltage which makes operation not possible at all time. Minor and major modifications process design of the plant will result in the dramatic improvement in the plant energy efficiency, the need for such modifications will be brought out by comparis on of

* Corresponding author:

bashirgarba2003@yahoo.com (Bashir Garba. I.)

Published online at http://journal.sapub.org/ijee

Copyright (C) 2012 Scientific \& Academic Publishing. All Rights Reserved specific energy consumption per unit product.

The actual use of electrical energy has been calculated/measured at the output of electrical equip ment in the preliminary audit, improving the efficiency of energy conversion process will result in lower loading levels in the electrical equipment and lower use of electrical energy. In examining the major low efficiency energy conversion processes and arrive at ways to reduce the energy consumption in those process. The possibility of using automatic controls in order to switch off electrical equip ment when the process does not really need energy and to adjust the efficient operation of electrical equipment against varying process load levels should be critically examined. It is often possible to reset the process variables to new levels conducive for lower energy consumption after a critical examination of the process.

The Ahmadu Bello University water supply treatment scheme was established in 1970, by the Estate Department of Ahmadu Bello University, with a view to independently meeting the university water supply demand.

The plant was designed to supply 13.64 million litres of portable water per day. It entails an impounded reservoir called kubanni Dam, water intake structures, water treatment works a booster station, main pressure pipeline and several small sized over-head tanks scattered over the campus.

The main pressure pipelines ranging from $350 \mathrm{~mm}$ in diameter to $75 \mathrm{~mm}$ distributes treated water from the treatment plant to all the low-pressure zones, these are:

\subsection{Treatment Plant}

This is where the raw water is treated and the treated water is finally pumped out to the University community. So many changes occurs in the treatment plant which also affect the 
loading condition of the pumps example replacement of the $600 \mathrm{Amps}$ electrical panel to $1000 \mathrm{sub}$ standard panel with no necessary protective safety devices, high lift pumps are of lower capacity and lower speed with high consumption with any installation of energy saver.

\subsection{Water De mand}

Water demands are based on the guideline set forth in the National University Commission Standards guide as follows:

1-Residentail population $=300$ litres per head 4 hours

On the bases of the above figures, the total demand for the samaru campus is shown below;

pumping system pumps and control panels including historical and present.

The main objective of this study is for the presentation of energy efficiency measure as bankable project and viable installation and to improve the overalle ffic iency of the plant.

\subsection{Methodol ogy}

The study involves the calculating daily operation of energy consumption of pump ing mach ines used for the water distribution at minimum and maximum voltage demand of operation, visual inspection and data collection of hours of operation for a period of one year. Total electrical energy consumption per day and total actual energy use per day, maximum VA demand, maximum $\mathrm{KW}$ demand, consumption figures of the whole pump in the plant, energy cost figures of the plant in KWh.

\subsection{Li mitation}

The following are the limitations of the project:

-The non-availability of power supply from PHCN delayed the realization of the hour of operation of pumps.

-Frequent voltage drop from $400 \mathrm{amps}$ to $300 \mathrm{amps}$ from the PHCN necessitate the use of generator.

-Pumps are not operated simultaneously.

-Preliminary Audit results are expressed in the form of load factor of the plant, power factor and average daily consumption.

-Electricity bill is centralized for the whole university the demand in KWh of electricity of can only calculated by the consumption of the unit by the PHCN charges which is $\mathrm{N} 8.50$ per KWh.

\section{Data Required on the Pump Operation}

Pump No 1, No2, No3, No4: Daily operation hours 6hour morning, 6hours afternoon, 6hours night, voltage requirement for daily operation of the pumps, isolations of pumps.

The Bar chart above shows the consumption rate in $\mathrm{kWh}$ on y axis and the cost of power in various hours of operation. At the first hour the operation, the consumption rate and cost of electricity is high which indicate good voltage of operation at the period, which is about 5:00am to 6:00a mat a voltage of 348 volt to 400 volt. While the fourth hour shows lower consumption and cost it a period of low voltage and very high demand of electricity within the campus which $12: 00 \mathrm{pm}$ to $1: 00 \mathrm{pm}$ afternoon. Energy consumption for the above working hours was conducted without the use of any energy conservation strategy.

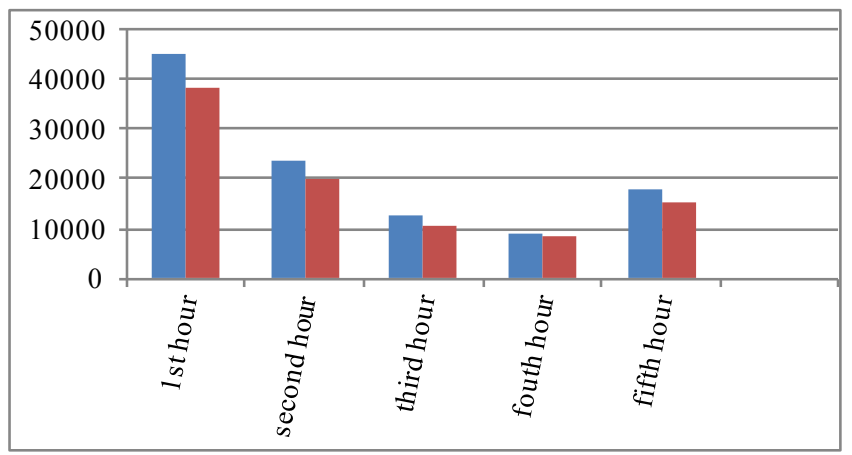

Firgure 1. Hours of running and Cost of Energy

Table 1. Water Demand

\begin{tabular}{|c|c|c|c|}
\hline Date & $\begin{array}{c}\text { Pumping } \\
\text { period(hour) }\end{array}$ & $\begin{array}{c}\text { Water } \\
\text { pumped(m3) }\end{array}$ & $\begin{array}{c}\text { Percentage } \\
\text { demand } \\
\mathbf{( \% )}\end{array}$ \\
\hline $09 / 02 / 2011$ & 13 hours & 2,990 & $96.5 \%$ \\
\hline $10 / 02 / 2011$ & 09 hours & 2,070 & $66.8 \%$ \\
\hline $11 / 02 / 2011$ & 20 hours & 4,600 & $148.4 \%$ \\
\hline $12 / 02 / 2011$ & 19 hours & 4,370 & $141.0 \%$ \\
\hline $13 / 02 / 2011$ & 19 hours & 4,370 & $141.0 \%$ \\
\hline $14 / 02 / 2011$ & 20 hours & 4,600 & $148.4 \%$ \\
\hline $15 / 02 / 2011$ & 1 hhours & 4,140 & $133.5 \%$ \\
\hline
\end{tabular}

The water supply to the university is taking from the water works lines which pass through the campus. The supply begins at the main station to other areas close to the water treatment plant and to the booster station for supply to the areas far from the water treatment plant.

Table 2.

\begin{tabular}{|c|c|c|}
\hline Time hrs & $\begin{array}{c}\text { Energy consumed } \\
\text { in }(\mathbf{k w h})\end{array}$ & $\begin{array}{c}\text { Energy cost at N8.5 } \\
\text { per (kwh) in Naira }\end{array}$ \\
\hline $1000-1110$ & 4532 & N38,522 \\
\hline $1140-1230$ & 2367 & $\mathrm{~N} 20,119.5$ \\
\hline $1250-1310$ & 1256 & $\mathrm{~N} 10,676$ \\
\hline $1340-1430$ & 1004 & $\mathrm{~N} 8,534$ \\
\hline $1530-1650$ & 1786 & $\mathrm{~N} 15,181$ \\
\hline $\begin{array}{c}\text { Whole working day } \\
(7.5 \mathrm{hrs})\end{array}$ & 10945 & $\mathrm{~N} 93,032$ \\
\hline
\end{tabular}

\subsection{Reduction of Actual Use of Electrical Energy}

The actual use of electrical energy has been calculated / measured at the output of electrical equipment in the audit. But the final value of electrical energy content in unit output will be less due to losses in energy conversion process. Improving the efficiency of energy covers ion process will result in lower loading levels in electrical equipment and lower use of electrical energy. As far as electrical energy 
conservation is concerned, reducing the use of electrical energy is the primary action phase in the hierarchy of conservation strategies.

\subsubsection{Load Management}

Examination of daily active and reactive load curves for typical day at the incomer will reveal the need for load management in the system. Load management at primary level as envisage here involves techniques aimed at improving the daily active power load factor and bringing it close to unity and techniques aimed at bringing down the daily average reactive load factor to unity.

\subsubsection{Reduction of Losses in Electrical Motors}

Minimization of losses in pumps is a good strategy considered during the study. Induction motors constitute 70 to $80 \%$ of electrical load hence reduction of losses in these motors assumes special significance, so loading level are minimize in the study by better utilization of energy in the energy conversion process.

\subsubsection{Motor Loading Analysis in Electrical Energy Audit}

-Classify the motors into various categories depending on type of loading viz. continuous constant load duty, continuous variable load duty, intermittent duty with or without starting/electrical braking, short time duty etc. In each category, we classify the motor into low HP, medium HP and high HP Classes.

-Short time duty motors all ratings may not offer much in terms of possible loss reduction, however, they may be used for peak shaving applications.

-Low HP motors may need only a cursory evaluation since the loss reduction achievable fro $m$ them may not be enough to justify the effort and expense. However, the final decision in this matter will depend on the number of such motors in the plant, their HP distribution, loading levels.

-The adequacy of rating (under rating or over rating or wrong type of motor etc, where checked in the study close attention was paid on duty with frequent starting/reversing/plugging etc.

-Determination of continuous constant load and continuous variable load which can offer possibilities of loss reduction. Their loading level must be determined, through load transfer.

Table 2.1. Hours of Operations

\begin{tabular}{|l|l|l|l|}
\hline $11 / 02 / 2011$ & 20 hours & 4,600 & $148.4 \%$ \\
\hline $12 / 02 / 2011$ & 19 hours & 4,370 & $141.0 \%$ \\
\hline $13 / 02 / 2011$ & 19 hours & 4,370 & $141.0 \%$ \\
\hline $14 / 02 / 2011$ & 20 hours & 4,600 & $148.4 \%$ \\
\hline $15 / 02 / 2011$ & 1 hours & 4,140 & $133.5 \%$ \\
\hline
\end{tabular}

The water supply to the university is taking from the water works lines which pass through the campus. The supply begins at the main station to other areas close to the water treatment plant and to the booster station for supply to the areas far from the water treatment plant.

\section{Energy Consumption Audit}

Almost all known energy conservation and management techniques aim at one or more reasons examp le, reduction of actual use of energy without much modification in the process design, reducing the payment to be made for energy and reduction of energy losses by identifying priority order, to arrive at a recommendations by introduction of new changes in operation, changes in sequence of operations, replacing inefficient equip ment/process with energy efficient equipment.

\subsection{Reduction of Actual Use of Electrical Energy}

The actual use of electrical energy has been calculated/measured at the output of electrical equipment in the preliminary audit. But final value of electrical energy content in unit output will be less than the value obtained due to losses in energy conversion process .Improving the efficiency of energy conversion process will result in lower loading levels in equipment and lower use of electrical energy.

\subsection{Auditing Tools}

The following tools were used during the study.

-Log book use for the record of daily operation of pumps.

-University electricity bill and charge per Kwh.

-Identification/verification of energy consumption and other parameters by measuring.

-Visual inspection

-Volt meter, ammeter

-Power analyser (measures active, reactive, apparent power, power factor energy consumed)

\subsection{Benchmarking}

Energy benchmarking involves the development of quantitative and qualitative indicator through the collection and analysis of energy and energy management practices. Benchmarking in simplistic terms is the process and to improve the standard of the process to improve quality of the system, product, services etc. It allows the research to develop plans on how to adopt best practice, usually with the aim of increasing some aspect of performance. assessment and logical evolution of avenues for improvement where emp loyed in this study .Historical data, well documented in this study which help to bring out energy consumption and cost trends month-wise /daily. Trend analysis of energy consumption, cost, relevant production features, specific energy consumption, help to understand effects of capacity utilization on energy use efficiency and cost on a broader scale.

\section{Results and Discussion}


The Study was conducted to create a data baseline energy measurement for reference during post implementation measurement and verification and presentation of efficiency measures as bankable project and viable installation by doing so quantifying energy losses and energy saving potential performance trends and specific energy consumption. This chapter present results obtained from the operation of the four selected most functional pumps in the plant.

\subsection{Pump Study}

Existing efficiency of the pump is evaluated by measuring of flow head and head losses and power, operating characteristics curves of pumps are known by the measurement of all parameters at various load conditions. Recommendation made to improve the overall efficiency pumping system with the review and understanding the operational conditions and process of operation of pumping system. Study pattern of operation of individual pumps including number of operating hours of the individual pumps for the past 12 month. Logged details of daily measurements like flow head, power parameters are referred to where available, and used as appropriate, in arriving at conclusion regarding energy measures.

Determination of power consumption of pumps while running the pumps in parallel, every minute data logging and power is made for a minimumperiod of 20 minutes.Based on this study suggestions were made.

Table 3. The Energy Calculations And Auditing

\begin{tabular}{|c|c|c|c|c|}
\hline Description & Units & formula & value & \\
\hline $\begin{array}{l}\text { Measured power } \\
\text { consumption of } \\
\text { the present } \\
\text { operat ing pump }\end{array}$ & $\mathrm{kw}$ & A & 29.1 & 30.0 \\
\hline $\begin{array}{c}\text { Calculated power } \\
\text { consumption of } \\
\text { proposed new low } \\
\text { head/flow } \\
\end{array}$ & kw & B & 10.5 & 21 \\
\hline $\begin{array}{c}\text { Annual power } \\
\text { saving }\end{array}$ & kwh & $\mathrm{D}=(\mathrm{A}-\mathrm{B}) \mathrm{C}$ & 135780 & \\
\hline $\begin{array}{c}\text { Power } \\
\text { cost(average) }\end{array}$ & $\begin{array}{c}\text { Naira/ } \\
\text { kwh }\end{array}$ & E & 8.5 & 8.5 \\
\hline $\begin{array}{l}\text { Recurring annual } \\
\text { cost saving }\end{array}$ & Naira & $\mathrm{F}=\mathrm{DxE}$ & 1154130 & \\
\hline $\begin{array}{c}\text { Average annual } \\
\text { operat ing hours of } \\
\text { one pump@20 per } \\
\text { day. } \\
\end{array}$ & Hours & $\mathrm{C}$ & 7300 & 7300 \\
\hline $\begin{array}{l}\text { One-time cost of } \\
\text { implementation } \\
\text { for } \\
\text { pump ,est imate } \\
\text { N180,000 }\end{array}$ & Naira & G & N720000 & $\begin{array}{c}\mathrm{N} 720 \\
000\end{array}$ \\
\hline Payback & month & $\mathrm{H}=\mathrm{G} / \mathrm{F} 12$ & 7.2 & 8.78 \\
\hline
\end{tabular}

\subsection{Energy Saving Calculations}

Annual energy savings, system modifications suggested, cost benefit analysis. Energy consumption patterns for the (PHCN), it has been assessed that the total consumption of energy and the amount paid to Power Holding Company of
Nigeria and the specific data on energy consumption for the water treatment plant which is on the estimate of the university consumption. However, with the data available about utilization of power in the campus and electricity bill over a period of one year has been gathered and computed on the whole university per month to a time of $81.41 \mathrm{M}$ wh out of which the water treatment plant has a lion's share off about $55 \%$.

Calculation for and recommendations, replacement of the existing normal pumps with inverter compatible energy efficient pump at Ahmadu Bello University water treatment plant (45kw with $30 \mathrm{kw}$ pump) which will reduce power consumption.

\section{Discussions}

To determine ways of reducing energy consumption per unit product or the lower operating cost, energy audit reduce the specific electrical consumption, and modification in plant processes also help in the reduction of consumption of energy .The need for such modification will be brought out by a comparison of specific energy consumption of the plant standard values pertaining to that particular product. Issues regarding process design were examined in energy audit as far as to their implication on reducing the load level on electrical equipment and reducing losses in the electrical system.

The intensity and depth of planned electrical energy audit will depend on a comparison between the best specific energy consumption figures of the product achieved in any industry on a world wide scale and figures for the plant in question or references values for specific energy consumption. The bulk metering give an overall estimate of the cost of electricity which fluctuate with time and error may occur in the process of reading the meter of otherwise, and also the university have very little control over their electricity cost.

\section{Conclusions and Recommendations}

\subsection{Conclusions}

The finding of the study serves as the basic for making the following conclusions;

$>$ There is an absolute power problem in the treatment plant basically low voltage.

$>$ Continuous duty rated motors are used for an intermittent duty with frequent starting, which increases losses.

$>$ The electricity consumed is not proportional to the production of water at the treatment plant.

$>$ Results obtained shows wrong types of pumps are use at the plant without any energy conservation employed during operation.

$>$ Electricity billing method use by the power Holding Company of Nigeria is not accurate. 


\subsection{Recommendations}

The following reco mmendations have been made based on the findings of this study.

$>$ The schedule of operation should be in line with the best practice of energy conservation to reflect on-peak, mid-peak and off peak periods.

$>$ Replacement of the existing normal pumps with inverter co mpatible energy efficient pump.

$>$ Good condition monitoring of pumps to reduce losses due to mechanical or electrical fau lt.

$>$ There is high energy wastage during operation so energy usage should be properly organized for optimum utilization.

The use of a prepaid meter in the water treatment plant will give a correct estimate of the cost of electricity.

$>$ The use of a time -of -use rates which measures electricity consumption in different periods of the day and week using smart meter to provide the university with a great control over electric ity cost.

\section{REFERENCES}

[1] Shaba, yusuf 2002 An investigation of Energy consumption Department of Mechanical Engineering Ahmadu Bello University zaria .

[2] Godwin,Ede 2006 An investigation of energy consumption per staffs and students of Ahmadu Bello University Zaria.

[3] Suresh, Kumar. K.S (2001) Electrical energy conservation and auditing in plant electrical distribution systems india.

[4] Chandraiah .V,Lakshmi P.B,Mahmood.V,(2010) Investment grading audit of pumping machinery at water treatment plant at mindi india.

[5] A.N.Energy consultancy (2001) Analysis of energy consumption at ACME Limited.

[6] Water supply committee report, (2004 Ahmadu Bello University zaria kaduna state Nigeria.

[7] Chris J. E, 1999 Electricity Distribution planning and forecasting case study of kiru local government Kano state Nigeria. Department of Electrical En gineering. 